\title{
Incidence and severity of postthrombotic syndrome after iliofemoral thrombosis - results of the Iliaca-PTS - Registry
}

\author{
Jamil Nawasrah,2 (10, Barbara Zydek ${ }^{3}$, Jessica Lucks ${ }^{3}$, Johannes Renczes ${ }^{1,3}$, \\ Barbara Haberichter ${ }^{1}$, Ümniye Balaban ${ }^{4}$, Sebastian Schellong ${ }^{5}$, \\ and Edelgard Lindhoff-Last ${ }^{1,3}$ \\ ${ }^{1}$ CCB Vascular Center, Cardiology Angiology Center Bethanienhospital (CCB), Frankfurt a. M., Germany \\ 2 Section of Angiology, Department of Cardiology/Cardiology I, University Medical Center Mainz, Johannes Gutenberg University, \\ Mainz, Germany \\ ${ }^{3}$ CCB Coagulation Research Center, Cardiology Angiology Center Bethanienhospital (CCB), Frankfurt a. M., Germany \\ ${ }^{4}$ Institute of Biostatistics and Mathematical Modelling, Goethe-University Frankfurt, Frankfurt a. M., Germany \\ ${ }^{5}$ Second Medical Department - Cardiology and Angiology, Municipal Hospital of Dresden, Dresden, Germany
}

\begin{abstract}
Summary: Background: Deep venous thrombosis (DVT) and in particular, iliofemoral thrombosis (IFT) can lead to recurrent thrombosis and postthrombotic syndrome (PTS). Data on the prevalence, predictors and outcome of IFT are scarce. Patients and methods: We retrospectively searched our database of outpatients who had presented with DVT and IFT including the iliac veins from 2014 until 2017. In addition, we performed a prospective registry in a subgroup of patients with IFT. These patients received duplex ultrasound, magnetic resonance venography and measurement of symptom-free walking distance using a standardized treadmill ergometry. The severity of PTS was analyzed using the Villalta-Scale (VS) and quality of life was assessed using the VEINES-QOL/Sym Questionnaire. Results: 847 patients were retrospectively identified with DVT and 19.7\% $(167 / 847)$ of these presented with IFT. 50.9\% (85/167) of the IFT-patients agreed to participate in the prospective registry. The majority of these patients (76.5\%: 65/85) presented with left-sided IFT. In 53.8\% (35/65) May-Thurner syndrome was suspected. 27.1\% (23/85) underwent invasive therapy. Moderate or severe PTS (VS $\geq 10$ ) occurred in 10.6\% (9/85). The severity of PTS is correlated with a reduced quality of life $(\rho(\mathrm{Cl} 95 \%)=-0.63(-0.76 ;-0.46) ; p<0.01)$. None of the patients presented with a venous ulcer at any time. A high body mass index was a significant predictor (OR $(\mathrm{Cl} 95 \%)=1.18(1.05 ; 1.33)$ $p=0.007)$ for the development of clinically relevant PTS (VS $\geq 10)$ and venous claudication. Conclusions: Every fifth patient with DVT presented with an IFT. The majority developed left sided IFT. Every $10^{\text {th }}$ patient developed moderate or severe PTS (VS $\geq 10$ ). A high body mass index was predictive for the development of PTS and venous claudication.
\end{abstract}

Keywords: Deep vein thrombosis, iliofemoral thrombosis, postthrombotic syndrome

\section{Introduction}

Postthrombotic syndrome (PTS) is a chronic complication of deep vein thrombosis (DVT) in the lower extremities and can occur in up to $20-50 \%$ of patients within 2 years after DVT [1-3]. It can impose significant morbidity and can be associated with a negative impact [4-7] on quality of life associated with disease severity $[8,9]$.

Factors potentially related to the development of the PTS are older age, obesity, a history of previous ipsilateral DVT, iliofemoral location of the current thrombosis, failure to promptly recover from the acute symptoms and insufficient quality of oral anticoagulant therapy [10, 11]. Furthermore, it is known that the severity of PTS correlates with the location of the DVT, the more proximal the more severe $[3,12]$.
The prevalence of iliofemoral thrombosis (IFT) as one major risk factor for developing PTS is not well known in the population. In the recent literature, exact prevalence data concerning IFT are lacking. Previous publications described proximal DVT which may include the common femoral vein with or without the iliac vein. May-Thurner syndrome (MTS) may be one of the major risk factors for the development of left sided IFT, but the prevalence of MTS in IFT patients is still unknown due to difficulties in diagnosing MTS [13].

We have therefore performed a retrospective registry in patients presenting with DVT and IFT to analyze the prevalence of IFT in the overall DVT population. In addition, we performed a prospective registry in a subgroup of patients with IFT who agreed to participate to document 
the severity of PTS, the occurrence of iliac vein compression syndrome in left-sided IFT and quality of life. Additional goals were to identify predictors for the development of severe PTS in this patient population.

\section{Patients and methods}

\section{Patients}

The CCB vascular center in Frankfurt is the biggest center for vascular diseases in the federal state of Hessen/Germany, where specialists in vascular medicine and vascular surgeons work together in an interdisciplinary team. The patients of our outpatient department are all-comers transferred from general practitioners, oncologists and other disciplines with suspected and finally diagnosed DVT in contrast to patients e.g. seen in University Medical Centers.

We searched the database of our outpatient department for patients who had presented with DVT in the period from 01-Jan-2014 until 30-Jun-2017. Keywords for the database query were: "pelvic vein thrombosis", "iliofemoral thrombosis", "deep vein thrombosis".

847 patients consulted our site in the mentioned period of time with present DVT at time of consultation or past DVT diagnosed after 1996. IFT including the iliac veins was identified in 167 of 847 (19.7\%) patients with DVT.

Patients with IFT were asked to be included in the prospective registry, if they fulfilled the following inclusion criteria:

- age between 18 to 80 years

- previously documented IFT by ultrasonography, phlebography, CT or MRI in 1996 or later

- agreement to participate by signing an informed consent.

85 of 167 (50.9\%) patients agreed to participate and were included for further analysis (patient screening see Figure 1).
With approval of the responsible ethics committee patient's written informed consent was obtained. All procedures performed were in accordance with the ethical standards of the institutional and/or national research committee and with the 1964 Helsinki Declaration and its later amendments or comparable ethical standards. The study was registered ClinicalTrials.gov ID: NCT03148548.

\section{Methods}

In addition to the medical history and clinical examination, the severity of the PTS was quantified using the Villalta-Scale (VS) and the impairment of quality of life (QOL) using the VEINES-QOL/Sym Questionnaire.

Ilio-caval and leg vein duplex-ultrasonography, treadmill ergometry and MR venography were performed under standardized conditions.

\section{Duplex ultrasonography (DUS)}

DUS was performed using the Siemens ACUSON X700. The veins were imaged with different transducers and positions based on their location and depth. The ilio-caval veins were examined with a 2 to $4 \mathrm{MHz}$ curvilinear transducer in a lying patient, whereas the deep femoral, popliteal and the infragenual veins were examined using a 4 to $7 \mathrm{MHz}$ linear array transducer while the patient was standing. Postthrombotic wall-changes and occlusions or the occurrence of May-Thurner syndrome were detected. All patients underwent a DUS.

\section{MR-venography (MRV)}

MR-Venography was performed with a 1.5 Tesla Siemens Sonata MRI using the contrast agent Dotarem in a dosage of $0.2 \mathrm{ml} / \mathrm{kg}$ bodyweight in order to detect potential existence and extent of postthrombotic changes in the ilio-caval veins, the existence of an iliac vein compression syndrome, hypo- or aplasia of the ilio-caval vein tract in accordance with DUS [14, 15]. MRV was performed in 75

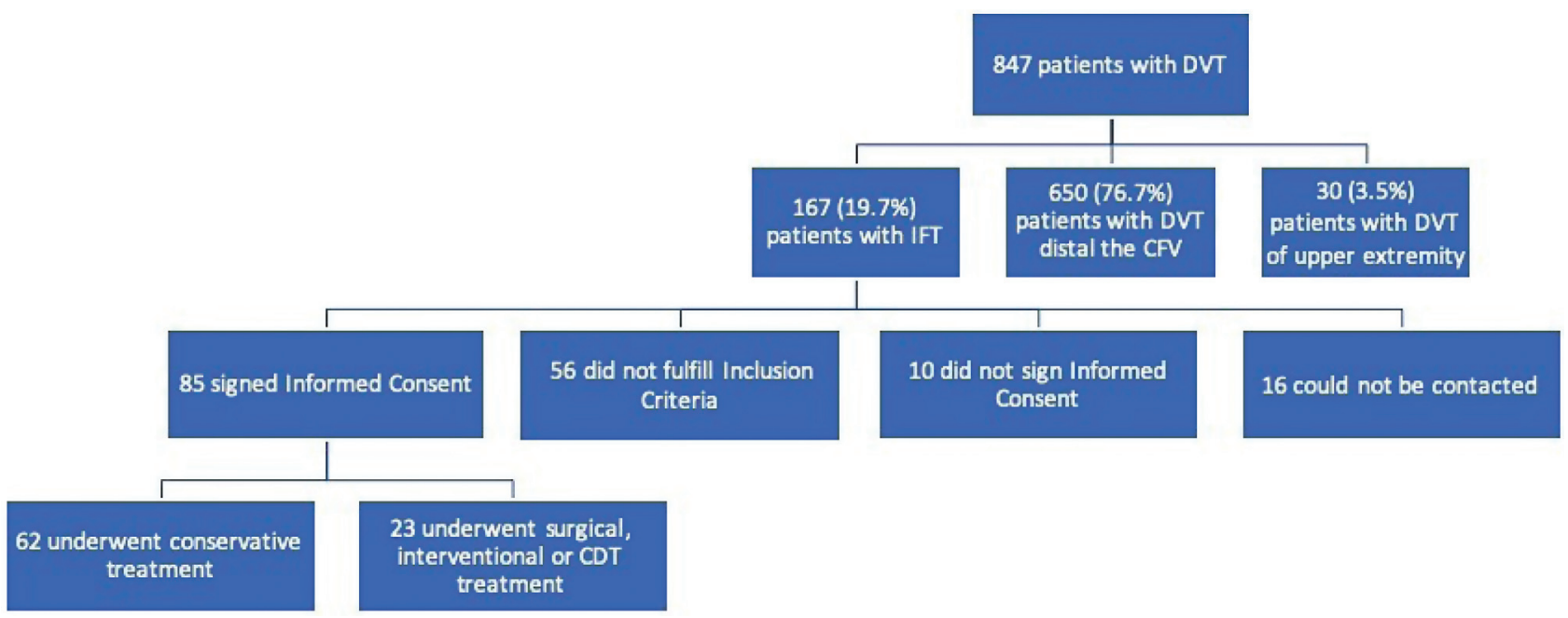

Figure 1. Patient screening. DVT: deep vein thrombosis; IFT: iliofemoral thrombosis; CFV: common femoral vein; CDT: catheter derived thrombolysis. 
patients. 10 patients could not be examined; 3 due to renal insufficiency, 2 due to claustrophobia, 1 due to known allergy against contrast-agents, 4 rejected with no reason.

\section{Definition of May-Thurner syndrome (MTS) and descending IFT}

MTS or iliac vein compression syndrome is caused by both mechanical and physiological factors; the chronic pulsatile compression of the left common iliac vein (LCIV) by the crossing right common iliac artery (RCIA) stimulates the formation of fibrotic adhesions that can cause partial or complete iliac vein obstruction over time $[15,16]$. To identify MTS DUS (including PW-Doppler) and MRV were used. There is no accurate definition for a hemodynamic relevant MTS in the literature. The anatomical existence of venous compression in the MRV alone does not give information about its hemodynamic relevance [13].

In our registry MTS was defined either when the typical anatomy was detected by the radiologist using MRV and/or by the vascular specialist using DUS.

In our registry only patients with previously documented IFT were included. Furthermore we defined an IFT as "descending", if postthrombotic wall changes were present in the common-iliac vein, the external-iliac vein and the common-femoral veins without postthrombotic changes in the superficial-femoral veins, popliteal veins and infragenual veins evaluated by DUS and MRV. An isolated persistent occlusion of the iliac veins without other postthrombotic wall changes was also defined as a "descending" IFT. An "ascending" IFT was defined, if postthrombotic wall changes were present starting in the infragenual deep veins, popliteal veins and/or femoral veins in addition to the iliac veins.

\section{Treadmill ergometry}

Unfortunately, there is no standardized tool for diagnosing venous claudication. Therefore, we used a treadmill-ergometry protocol, which we use to evaluate walking ability in patients with peripheral artery disease [17, 18]. Patients had to walk $250 \mathrm{~m}$ with a pitch of $10 \%$ and a speed of $3.2 \mathrm{~km}$ per hour. Patients were asked, if they had symptoms like cramps, pain or heaviness in their legs. We defined and documented venous claudication (VC), if any of these symptoms occurred during or after the exercise. Both legs were evaluated.

84 patients underwent this examination, 1 patient could not be examined due to disability.

\section{Villalta Score (VS)}

The VS is a diagnostic scale for the PTS. It can be used to diagnose and categorize the severity of the condition and is a reliable, valid, acceptable and responsive measure of PTS in patients with previous, objectively confirmed DVT [19]. Five symptoms (pain, cramps, heaviness, paresthesia, pruritus) and six clinical signs (pretibial edema, skin induration, hyperpigmentation, redness, venous ectasia, pain on calf compression) are documented. Points are given for each of these 11 descriptors according to severity, ranging from 0 for not present to 3 for severe symptoms. Furthermore, if a venous ulcer is present, the severity of the condition is classified as high, regardless of the presence or absence of other signs or symptoms. The patient is diagnosed as having PTS, if the Villalta score is $\geq 5$ or if a venous ulcer is present. A score of 5-9 defines mild disease, $10-14$ moderate disease, and $\geq 15$ severe disease. We performed the Villalta-score addressing the affected leg in all patients included in the registry.

\section{VEINES-QOL/Sym questionnaire}

The VEINES-QOL/Sym is a patient-based questionnaire designed for self-completion (VEINES $=$ Venous Insufficiency Epidemiological and Economic Study). The content and format of questionnaire-items and response scales were modelled after the SF-36 (Short Form) questionnaire, which was developed in the mental health care to evaluate and measure outcome in terms of quality of life and symptom improvement in psychiatric treatment. Generic SF-36 questions were modified to make them specific to venous disease, and new venous-disease-specific questions were developed using the same format and response scales of the SF-36 [20].

The 26-item questionnaire measures the impact of deep venous thrombosis on symptoms (VEINES-Sym scale) and quality of life (VEINES-QOL scale) from the patient's perspective. The items cover symptoms (10 items), limitations in daily activities ( 9 items), time of day of greatest intensity (1 item), change over the past year (1 item), and psychological impact (5 items). Responses are rated on two-point to seven-point Likert response scales of intensity, frequency or agreement. The time frame for questions about symptoms, daily limitations, and psychological impact covers the previous 4 weeks, as in the SF-36. For both the VEINES-QOL and VEINES-Sym scales, high scores indicate better outcomes. It proved to be a practical, reliable, valid and accessible tool to measure quality of life, outcome and symptoms in adult patients with VTE in the past history [21-23]. Every patient included in the registry had to fill in the questionnaire.

\section{Statistical analysis}

Categorical variables are presented as frequencies and percentage and continuous variables as mean \pm standard deviation (SD) or median [min-max] as appropriate. Categorical variables were compared with the Chi-square test or Fisher's exact test and continuous variables with the Wilcoxon-Mann-Whitney-U-Test. A two-sided level of $\mathrm{p} \leq 0.05$ was considered as significant. The associations between Villalta scores and BMI, gender or age were evaluated by calculation of bivariate Spearman's correlation coefficient $\rho$. Confidence intervals for correlations were calculated using a basic bootstrap approach with 1000 replicates. Further univariate and multivariate logistic regression analysis were performed among the variables age, gender, BMI, MTS, DVT and Treatment. 
Statistical analyses were performed using SPSS software version 26.0 (IBM, Armonk, NY, USA) for Windows.

\section{Results}

\section{Prevalence of iliofemoral thrombosis (IFT)}

We identified 847 patients presenting with DVT. $35.0 \%$ (296/847) patients were diagnosed to have a distal DVT, $41.8 \%(354 / 847)$ patients presented with a proximal DVT excluding the common femoral vein and $19.7 \%(167 / 847)$ patients were identified to have IFT including the iliac veins (see Table I).

\section{Characteristics of patients with IFT included in the prospective registry}

$50.9 \%(85 / 167)$ of patients with IFT agreed to be included in the registry for further analysis. The index event had occurred on average 4 years (range: 0-20 years) before the time of the investigation.

$52.9 \%(45 / 85)$ were female. $76.5 \%(65 / 85)$ had a leftsided IFT, $15.3 \%(13 / 85)$ had a right-sided IFT, and $8.2 \%$ (7/85) presented with bilateral IFT. In the majority of patients $(69.4 \%$; 59/85) a "descending" IFT was diagnosed.

In $53.8 \%(35 / 65)$ of patients with left-sided IFT, MayThurner syndrome (MTS) was suspected. "Descending" IFT occurred in $69.2 \%(45 / 65)$ of patients with left-sided IFT and $77.8 \%(35 / 45)$ of these were diagnosed with MTS (see Table II).

$27.1 \%(23 / 85)$ of patients with IFT had undergone surgical, interventional or catheter-directed thrombolytic (CDT) therapy while $72.9 \%(62 / 85)$ had received conservative treatment (anticoagulation and compression stockings). Patients in the interventional group were significantly younger (median age 34.0 [16-59] vs. 46.5 [14-76] years, $\mathrm{p}=0.021)$ and presented more often with MTS (77.8\% vs. $44.7 \%, \mathrm{p}=0.025$ ) (see Table II).

\section{Villalta Score (VS)}

$57.6 \%(49 / 85)$ of the patients had a VS $<5$ (no PTS) and $31.8 \%(27 / 85)$ had a VS of 5-9 (mild PTS). Moderate or severe PTS (VS $\geq 10$ ) was observed in $10.6 \%$ (9/85) of the patients (see Figure 2). No patient had an active or healed venous ulcer, neither in medical history, nor when presenting in the outpatient clinic. No significant differences between conservatively and interventionally treated patients were observed.

The VS did not differ between men and women. No significant difference of the VS was observed comparing the ascending IFT-group with the descending IFT-group (VS: median 4 [0-12] vs. VS: median 3 [0-22], $\mathrm{p}=0.578$ ) and comparing the IFT-group with no MTS with the IFT-group
Table I. Prevalence of different types of deep vein thrombosis (screening period: 2014-2017)

\begin{tabular}{lc}
\hline Type of DVT & $\begin{array}{c}\text { Patients with DVT } \\
\mathrm{n}=847(\%)\end{array}$ \\
\hline Distal DVT; n (\%) & $296(35.0)$ \\
Femoro-popliteal DVT; n (\%) & $354(41.8)$ \\
Iliofemoral DVT; $\mathrm{n}(\%)$ & $167(19.7)$ \\
DVT of upper limb; $\mathrm{n}(\%)$ & $30(3.5)$ \\
\hline
\end{tabular}

DVT: Deep Vein Thrombosis; Distal DVT: DVT of one or more infragenual or muscle veins; Femoro-popliteal DVT: DVT of infragenual, popliteal and femoral veins; Iliofemoral DVT: Femoro-popliteal DVT including the iliac veins or isolated iliac vein thrombosis.

with MTS (no MTS VS: 4 [0-22], MTS VS: 3 [0-19], $\mathrm{p}=0.868)$.

Analysing the severity of the PTS in dependence of the time after the event we did not observe a relevant increase of the VS during a period of 20 years regardless of the type of therapy (conservative or interventional treatment) (see Figure 3).

\section{Venous claudication}

The prevalence of venous claudication in the overall study population was $10.6 \%(9 / 85)$ and was numerically slightly different between the conservative and the interventional group (9.7\% vs. $13.0 \%$; $=0.698)$. Patients with moderate or severe PTS (VS $\geq 10$ ) presented more often with venous claudication compared to patients with no or mild PTS (VS < 10) $(22.2 \%(2 / 9)$ vs. $9.2 \%(7 / 76), \mathrm{p}=0.242)$.

\section{Quality of life}

Quality of Life in the overall study population was high (combined VEINES-QOL/Sym-Score: median 86 [38103]). Comparison of the VEINES Scores revealed no significant difference between the conservative and the interventional treatment group (combined VEINES-QOL/ Sym-Score: median 88 [38-103] versus 83 [51-103]; $\mathrm{p}=$ 0.839 ) (see Table III). A high negative correlation between the VEINES Score and the severity of the PTS was observed $(\rho($ CI 95\%) $=-0.63(-0.76 ;-0.46) ; p<0.01)$ (see Figure 4).

\section{Predictors for PTS and venous claudication}

Using the univariate logistic regression analysis a high BMI was identified as a significant predictor for developing a moderate or severe PTS (VS $\geq 10$ ). Other variables as age, gender, existence of May-Thurner syndrome, type of DVT (ascending or descending) or the type of therapy (conservative or interventional) were not independent predictors for clinically relevant PTS. To verify this result a multivariate logistic regression analysis was performed in 
Table II. Baseline characteristics of patients with IFT who agreed to participate in the prospective registry

\begin{tabular}{|c|c|c|c|c|}
\hline & $\begin{array}{c}\text { All } \\
\mathrm{n}=85\end{array}$ & $\begin{array}{l}\text { Conservative therapy } \\
\qquad n=62\end{array}$ & $\begin{array}{l}\text { Interventional therapy } \\
\qquad n=23\end{array}$ & $p$-value \\
\hline Age; median [min-max] & $40.0[15-76]$ & $46.5[15-76]$ & $34.0[16-59]$ & 0.021 \\
\hline Female; n (\%) & $45(52.9)$ & $32(51.6)$ & $13(56.5)$ & 0.808 \\
\hline BMI; median [min-max] & $27[19-46]$ & $27[19-46]$ & $25[20-44]$ & 0.414 \\
\hline BMI 18.5-24.9; n (\%) & $27(31.8)$ & $17(27.4)$ & $10(43.5)$ & 0.269 \\
\hline BMI 25-29.9; n (\%) & $37(43.5)$ & $30(48.4)$ & $7(30.4)$ & \\
\hline $\mathrm{BMI} \geq 30 ; \mathrm{n}(\%)$ & $21(24.7)$ & $15(24.2)$ & $6(26.1)$ & \\
\hline $\begin{array}{l}\text { Period of time (years) } \\
\text { between occurrence of IFT } \\
\text { and examination; median } \\
\text { [min-max] }\end{array}$ & $4[0-20]$ & $3[0-20]$ & $5[1-17]$ & 0.363 \\
\hline IFT right-sided; n (\%) & $13(15.3)$ & $12(19.4)$ & $1(4.4)$ & 0.058 \\
\hline IFT both-sided; n (\%) & 7 (8.2) & $3(4.8)$ & $4(17.4)$ & \\
\hline IFT left-sided; n (\%) & $65(76.5)$ & $47(75.8)$ & $18(78.3)$ & \\
\hline $\begin{array}{l}\text { IFT left-sided with MTS; } \\
\text { n (\%) }\end{array}$ & $35(53.8)^{*}$ & $21(44.7)^{\star}$ & $14(77.8)^{*}$ & 0.025 \\
\hline "Ascending" IFT; n (\%) & $26(30.6)$ & $21(33.9)$ & $5(21.7)$ & 0.427 \\
\hline “Descending” IFT; n (\%) & $59(69.4)$ & $41(66.1)$ & $18(78.3)$ & \\
\hline
\end{tabular}

BMI: body-mass-index; IFT: iliofemoral thrombosis; DVT: deep vein thrombosis; MTS: May-Thurner syndrome. *Based on patients with left-sided IFT.

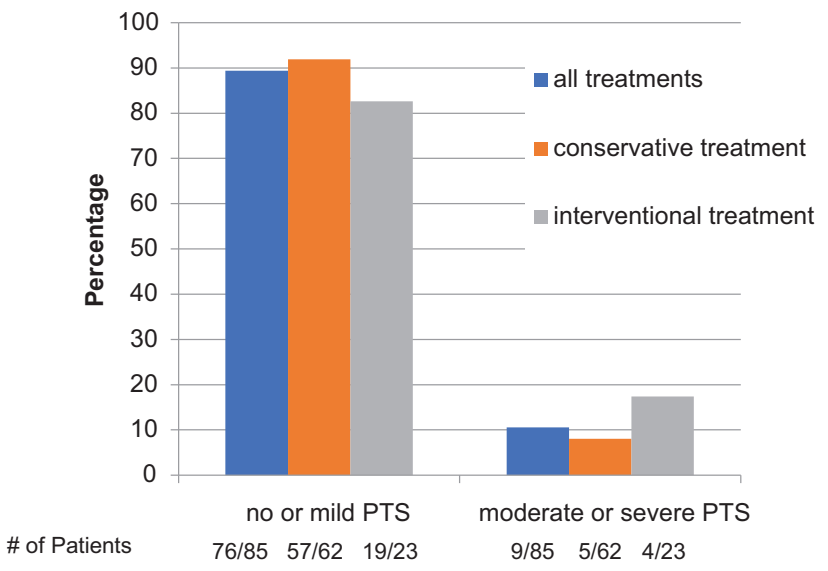

Figure 2. Occurrence of postthrombotic syndrome defined by the Villalta Score. PTS: postthrombotic syndrome; No or mild PTS: Villalta Score < 10; moderate or severe PTS: Villalta Score $\geq 10$.

addition. Again BMI was the only significant predictor for a moderate or severe PTS (VS $\geq 10$ ) (see Table IV).

Similar results were observed when analyzing predictors for venous claudication: a high BMI was a significant predictor for the development of venous claudication (OR 1.155 [95\% CI: 1.029-1.295]; $p=0.014$ ).

\section{Discussion}

Although the most common location of DVT is a femoropopliteal or distal thrombosis, iliofemoral thrombosis was diagnosed in nearly $20 \%$ of the examined population with DVT. Additionally, in the majority of patients the IFT was located on the left side. Left sided "descending" IFT was associated with MTS, which suggests that MTS might be one of the major risk factors for the development of this type of IFT. Although many uncertainties exist regarding the prevalence of MTS and its pervasiveness in DVT [13] our registry provides for the first time a systematic analysis of the possible relationship between left sided "descending" IFT and MTS as a possible reason.

Reported prevalences of PTS after DVT differ widely among studies because of differences in study populations, tools used to assess PTS and time interval between acute DVT and PTS assessment. Up to 10\% will develop severe PTS [24]. So far it has been assumed that the risk of developing moderate or severe PTS is increased in patients with IFT compared to patients with proximal lower limb DVT excluding the iliac veins or compared to infrapopliteal DVT [24].

In our registry, the majority of patients with IFT had no or mild PTS and moderate or severe PTS was observed in every tenth patient while none of them had developed a venous ulcer at any time. In the recently published prospective CACTUS-PTS-study the long-term risk to develop moderate or severe postthrombotic syndrome after symptomatic distal deep vein thrombosis (VS $\geq 10$ ) was $7 \%$ after 6 years of follow up [25] and was therefore not much different to our findings although focusing on distal DVT.

Ende-Verhaar analyzed the short and long-term incidence of PTS in patients included in the MEGA-study. No differentiation between proximal DVT including the iliac veins and distal DVT was performed. After one year the incidence of severe PTS (VS $\geq 7$ ) was $5.6 \%$ for all types of DVT which decreased to $2.1 \%$ after 8 years [26]. They could show that the symptoms of PTS improved many years after the index event in a large proportion of cases. This may be an explanation for our findings that the severity of PTS did not change over time.

As one can expect it could be demonstrated in our registry that the grade of PTS had a significantly high negative 


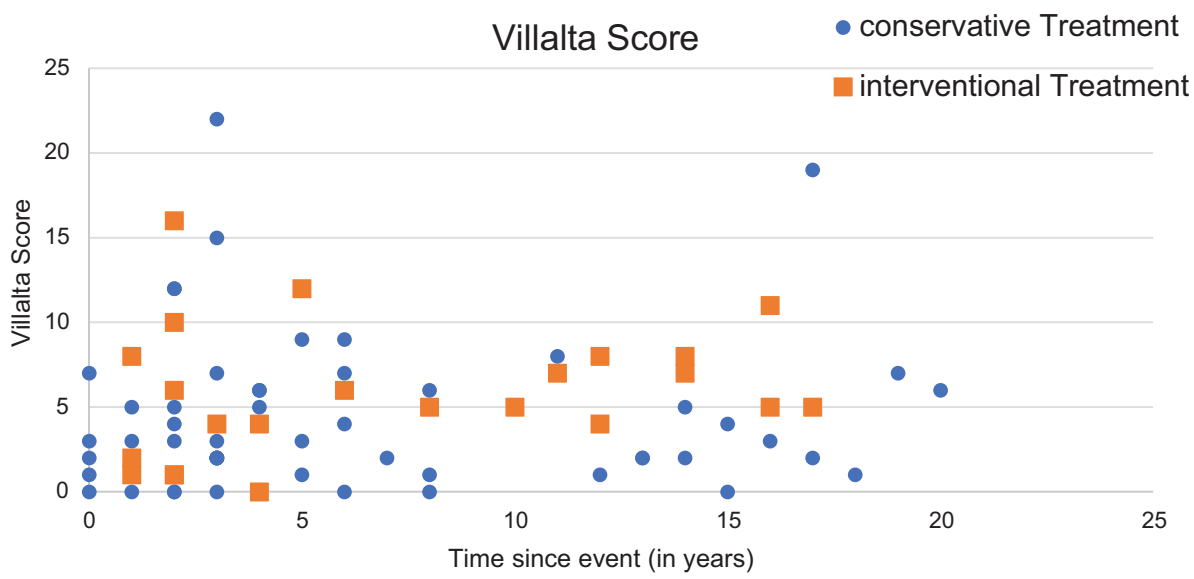

Figure 3. Scatter Plot of the Villalta Score depending on the period of time (years) after the occurrence of IFT ( $n=85)$, $(\rho(C I 95 \%)$ for conservative Treatment $=0.15(-0.09 ; 0.39), p=0.232 ; \rho(C l 95 \%)$ for interventional Treatment $=0.26(-0.19 ; 0.66), p=0.224)$.

Table III. Results of the Quality of Life - VEINES Scores (higher score indicates better outcome), Wilcoxon-Mann-Whitney-U-Test

\begin{tabular}{|c|c|c|c|c|}
\hline VEINES-Scores & $\begin{array}{c}\text { All } \\
\mathrm{n}=85\end{array}$ & $\begin{array}{c}\text { Conservative } \\
n=62\end{array}$ & $\begin{array}{l}\text { Interventional } \\
\qquad n=23\end{array}$ & p-value \\
\hline Clinical Symptoms (VEINES-Sym score) median [min-max] & $41[14-48]$ & $40.5[14-48]$ & $41[20-46]$ & 0.448 \\
\hline Quality of life (VEINES-QOL score), median [min-max] & $46[24-57]$ & $46.5[24-57]$ & $45[24-57]$ & 0.452 \\
\hline Combined VEINES-QOL/Sym score median [min-max] & $86[38-103]$ & $88[38-103]$ & 83 [51-103] & 0.839 \\
\hline
\end{tabular}

Table IV. Uni- and multivariate analysis of risk factors for moderate or severe PTS (Villalta Score $\geq 10$ )

\begin{tabular}{|c|c|c|c|c|}
\hline \multirow[b]{2}{*}{ Variable } & \multicolumn{2}{|c|}{ Univariate } & \multicolumn{2}{|c|}{ Multivariate } \\
\hline & Odds ratio $(95 \% \mathrm{Cl})$ & $p$-value & Odds ratio $(95 \% \mathrm{Cl})$ & $\mathrm{p}$-value \\
\hline Age & $1.018(0.982-1.055)$ & 0.341 & $1.059(0.991-1.131)$ & 0.088 \\
\hline \multicolumn{5}{|l|}{ Gender } \\
\hline Male & $0.527(0.123-2.263)$ & 0.389 & $0.370(0.047-2.877)$ & 0.342 \\
\hline female & Reference & & & \\
\hline BMI & $1.182(1.048-1.333)$ & 0.007 & $1.237(1.035-1.477)$ & 0.019 \\
\hline \multicolumn{5}{|l|}{ MTS } \\
\hline Yes & $3.241(0.752-13.973)$ & 0.115 & $7.984(0.469-135.959)$ & 0.151 \\
\hline No & Reference & & & \\
\hline \multicolumn{5}{|l|}{$\mathrm{IFT}$} \\
\hline Ascending & $0.619(0.120-3.205)$ & 0.568 & $1.495(0.079-28.159)$ & 0.788 \\
\hline Descending & Reference & & & \\
\hline \multicolumn{5}{|l|}{ Treatment } \\
\hline Conservative & $0.417(0.101-1.713)$ & 0.225 & $0.181(0.021-1.582)$ & 0.122 \\
\hline Interventional & Reference & & & \\
\hline
\end{tabular}

BMI: Body-Mass Index; MTS: May-Thurner syndrome; IFT: Iliofemoral Thrombosis.

impact on the quality of life. Therefore avoidance of severe PTS is one of the major goals to increase quality of life after occurrence of IFT in this patient population.

In our prospective registry nearly every third patient received interventional treatment. These patients were younger on average and presented mainly with left sided IFT and MTS. The incidence of PTS of the interventionally treated patients was comparable to the conservatively treated patients.

In prospective randomized trials conflicting outcomes concerning the prevention of posthrombotic syndrome have been published when comparing additional catheter-directed thrombolysis (CDT) to standard therapy (ST) [27-29]:

In the CAVA-trial the incidence of PTS was analyzed in patients with complete or partial thrombosis of the common femoral vein or more cranial vein segments after 12 months [28]. No significant difference of PTS was observed in the two groups (29\% in the CDT group vs. $35 \%$ in ST group (OR 0.75 [95\% CI 0.38-1.50]; $\mathrm{p}=0.42$ ).

In the ATTRACT-trial the incidence of PTS was determined in patients with femoral, common femoral, or iliac vein thrombosis after 6 and 24 months [29]. Again PTS was not significantly different between the interventional 


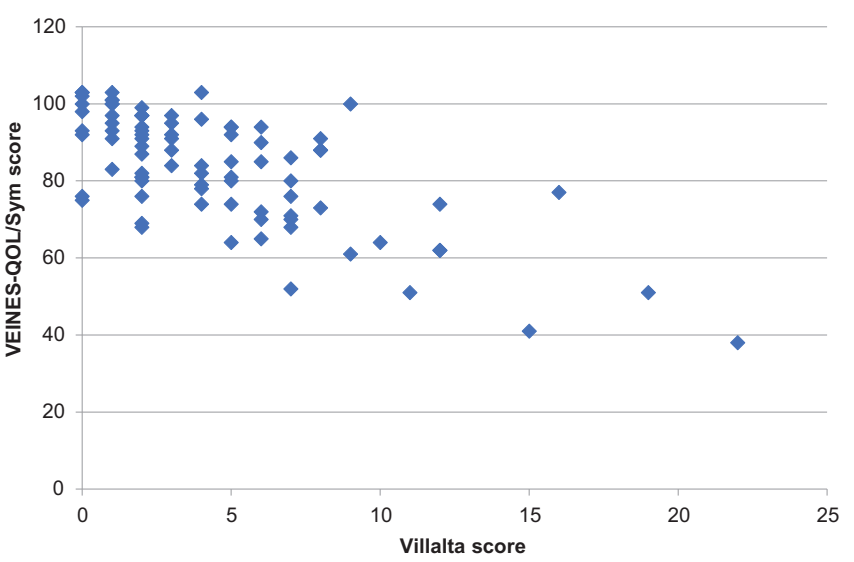

Figure 4. Correlation Analysis between quality of life (combined VEINES-QOL/Sym Score, higher score indicates better outcome) and postthrombotic syndrome (Villalta Score) $(\rho(\mathrm{Cl} 95 \%)=-0.63(-0.76 ;-0.46), p<0.01)$.

group compared to the standard group (47\% vs. $48 \%$; OR 0.96 [95\% CI 0.82-1.11]; $\mathrm{p}=0.56$ after 24 months).

In the CaVenT-trial the incidence of PTS in patients with a DVT above mid-thigh level was analyzed after 24 months [27]. A significantly lower incidence of PTS was observed in the interventional group compared to the standard treatment group (41.1\% vs. 55.6\%; OR 0.75 [95\% CI $0.2-$ 27.9]; $p=0.047)$. In contrast to these trials the involvement of the iliac veins was the main criteria for inclusion in our prospective registry.

We could identify a high BMI as the major independent predictor for the development of a moderate to severe PTS and of venous claudication in IFT patients which is in accordance with the current literature [30,31]. Rabinovich et al. described a doubling of the risk of developing PTS (OR 2.17, $\mathrm{p}=0.008$ ), when the BMI was $\geq 35 \mathrm{~kg} / \mathrm{m}^{2}$ [30]. Rattazzi et al. could show that patients with PTS presented with a significantly higher BMI than DVT-patients without PTS ( $p=0.005)$ [32]. Obesity $\left(\mathrm{BMI}>30 \mathrm{~kg} / \mathrm{m}^{2}\right.$ ) more than doubles the risk of PTS and weight loss may be a useful measure to reduce the risk of developing PTS, although not yet proven in literature [24].

\section{Limitations}

There are some limitations of the registry: Patients presenting with an IFT were not randomized neither to the conservatively nor to the interventionally treated cohort. It could well be that only severely affected patients were treated interventionally while patients with milder symptoms received conservative treatment only. In addition, the two examined cohorts in our registry are not big enough to observe significant differences between different treatment options. In addition, the interventionally treated group was very heterogenous and included patients who had received thrombectomy and AV-fistula, percutaneous interventions with or without stenting and/or catheter-directed thrombolysis.

The type and duration of the anticoagulant therapy after diagnosis of DVT could not be documented partly due to poor patients' memory and the retrospective design of data documentation at inclusion.

\section{Conclusions}

IFT is frequently observed in DVT. None of the patients with IFT presented with a venous ulcer, 10\% developed moderate or severe PTS and $10 \%$ presented with venous claudication.

One could cautiously conclude that with conservative therapy the results with regard to the occurrence of a postthrombotic syndrome may not be all that bad and possibly only a few patients might benefit from revascularization. One could further discuss that based on our data it could probably be more beneficial to wait a certain time before revascularization in the case of fresh descending thrombosis, whether the conservative therapy is effective and only to revascularize the minority of patients who after 6 Months are still severely symptomatic.

Prospective trials with randomization for interventional or conservative treatment in case of acute IFT explicitly including the iliac veins are needed. These results will help to decide whether acute interventions can improve the outcome of PTS in this patient population.

Since the majority of patients with conservatively treated IFT present with no or mild symptoms of PTS, patients with moderate to severe PTS and/or venous claudication might profit most from modern interventional strategies.

\section{References}

1. Prandoni P, Kahn SR. Post-thrombotic syndrome: prevalence, prognostication and need for progress. $\mathrm{Br} J$ Haematol. 2009;145(3):286-95.

2. Kahn SR, Galanaud JP, Vedantham S, Ginsberg JS. Guidance for the prevention and treatment of the post-thrombotic syndrome. J Thromb Thrombolysis. 2016;41(1):144-53.

3. Kahn SR, Shrier I, Julian JA, Ducruet T, Arsenault L, Miron MJ, et al. Determinants and time course of the postthrombotic syndrome after acute deep venous thrombosis. Ann Intern Med. 2008;149(10):698-707 
4. Rabinovich A, Kahn SR. The postthrombotic syndrome: current evidence and future challenges. J Thromb Haemost. 2017:15(2):230-41.

5. Broholm R, Sillesen H, Damsgaard MT, Jorgensen M, Just S, Jensen LP, et al. Postthrombotic syndrome and quality of life in patients with iliofemoral venous thrombosis treated with catheter-directed thrombolysis. J Vasc Surg. 2011;54 (6 Suppl):18S-25S.

6. Kahn SR, Shbaklo H, Lamping DL, Holcroft CA, Shrier I, Miron $\mathrm{MJ}$, et al. Determinants of health-related quality of life during the 2 years following deep vein thrombosis. J Thromb Haemost. 2008;6(7):1105-12.

7. van Korlaar I, Vossen C, Rosendaal F, Cameron L, Bovill E, Kaptein A. Quality of life in venous disease. Thromb Haemost. 2003:90(1):27-35.

8. Kahn SR, Hirsch A, Shrier I. Effect of postthrombotic syndrome on health-related quality of life after deep venous thrombosis. Arch Intern Med. 2002;162(10):1144-8.

9. Roberts LN, Patel RK, Donaldson N, Bonner L, Arya R. Postthrombotic syndrome is an independent determinant of health-related quality of life following both first proximal and distal deep vein thrombosis. Haematologica. 2014;99(3): e41-3.

10. Chitsike RS, Rodger MA, Kovacs MJ, Betancourt MT, Wells PS, Anderson DR, et al. Risk of post-thrombotic syndrome after subtherapeutic warfarin anticoagulation for a first unprovoked deep vein thrombosis: results from the REVERSE study. J Thromb Haemost. 2012;10(10):2039-44.

11. Van Dongen CJJ, Prandoni P, Frulla M, Marchiori A, Prins MH, Hutten BA. Relation between quality of anticoagulant treatment and the development of the postthrombotic syndrome. J Thromb Haemost. 2005;3(5):939-42.

12. Tick LW, Kramer MHH, Rosendaal FR, Faber WR, Doggen CJM. Risk factors for post-thrombotic syndrome in patients with a first deep venous thrombosis. J Thromb Haemost. 2008; 6(12):2075-81.

13. Harbin MM, Lutsey PL. May-Thurner syndrome: History of understanding and need for defining population prevalence. J Thromb Haemost. 2020;18(3):534-42.

14. Gurel K, Gurel S, Karavas E, Buharalioglu Y, Daglar B. Direct contrast-enhanced MR venography in the diagnosis of MayThurner syndrome. Eur J Radiol. 2011;80(2):533-6.

15. McDermott S, Oliveira G, Ergul E, Brazeau N, Wicky S, Oklu R. May-Thurner syndrome: can it be diagnosed by a single MR venography study? Diagn Interv Radiol 2013;19(1):44-8.

16. Brinegar KN, Sheth RA, Khademhosseini A, Bautista J, Oklu R. Iliac vein compression syndrome: Clinical, imaging and pathologic findings. World J Radiol. 2015;7(11):375-81.

17. Falkensammer J, Gasteiger S, Polaschek B, Gruber I, Frech A, Fraedrich $G$, et al. Reliability of constant-load treadmill testing in patients with intermittent claudication. Int Angiol. 2012;31(2):150-5.

18. Nicolai SP, Viechtbauer W, Kruidenier LM, Candel MJ, Prins $\mathrm{MH}$, Teijink JA. Reliability of treadmill testing in peripheral arterial disease: a meta-regression analysis. J Vasc Surg. 2009;50(2):322-9.

19. Kahn SR. Measurement properties of the Villalta scale to define and classify the severity of the post-thrombotic syndrome. J Thromb Haemost. 2009;7(5):884-8.

20. Newnham EA, Harwood KE, Page AC. Evaluating the clinical significance of responses by psychiatric inpatients to the mental health subscales of the SF-36. J Affect Disord. 2007;98(1):91-7.

21. Kahn SR, Lamping DL, Ducruet T, Arsenault L, Miron MJ, Roussin A, et al. VEINES-QOL/Sym questionnaire was a reliable and valid disease-specific quality of life measure for deep venous thrombosis. J Clin Epidemiol. 2006;59(10):1056. e1-e4.

22. Bland JM, Dumville JC, Ashby RL, Gabe R, Stubbs N, Adderley $U$, et al. Validation of the VEINES-QOL quality of life instru- ment in venous leg ulcers: repeatability and validity study embedded in a randomised clinical trial. BMC Cardiovasc Disord. 2015;15:85.

23. Lamping DL, Schroter S, Kurz X, Kahn SR, Abenhaim L. Evaluation of outcomes in chronic venous disorders of the leg: Development of a scientifically rigorous, patient-reported measure of symptoms and quality of life. J Vasc Surg. 2003;37(2):410-9.

24. Galanaud JP, Monreal M, Kahn SR. Epidemiology of the postthrombotic syndrome. Thromb Res. 2018;164:100-9.

25. Galanaud JP, Righini M, Le Collen L, Douillard A, Robert-Ebadi $H$, Pontal D, et al. Long-term risk of postthrombotic syndrome after symptomatic distal deep vein thrombosis: The CACTUSPTS study. J Thromb Haemost. 2020;18(4):857-64.

26. Ende-Verhaar YM, Tick LW, Klok FA, Huisman MV, Rosendaal FR, le Cessie S, et al. Post-thrombotic syndrome: Short and long-term incidence and risk factors. Thromb Res. 2019;177:102-9.

27. Enden T, Wik HS, Kvam AK, Haig Y, Klow NE, Sandset PM. Health-related quality of life after catheter-directed thrombolysis for deep vein thrombosis: secondary outcomes of the randomised, non-blinded, parallel-group CaVenT study. BMJ Open. 2013;3(8):e002984.

28. Notten $P$, ten Cate-Hoek AJ, Arnoldussen CWKP, Strijkers $\mathrm{RHW}$, de Smet AAEA, Tick LW, et al. Ultrasound-accelerated catheter-directed thrombolysis versus anticoagulation for the prevention of post-thrombotic syndrome (CAVA): a singleblind, multicentre, randomised trial. Lancet Haematol. 2020; 7(1):e40-e9.

29. Vedantham S, Goldhaber SZ, Julian JA, Kahn SR, Jaff MR, Cohen DJ, et al. Pharmacomechanical catheter-directed thrombolysis for deep-vein thrombosis. N Engl J Med. 2017;377(23):2240-52.

30. Rabinovich A, Ducruet T, Kahn SR. Development of a clinical prediction model for the postthrombotic syndrome in a prospective cohort of patients with proximal deep vein thrombosis. J Thromb Haemost. 2018;16(2):262-70.

31. Mol GC, Dronkers CEA, van de Ree MA, van der Pas SL, Tegelberg-Stassen M, Sanders FBM, et al. Elastic compression stockings one year after DVT diagnosis: Who might discontinue? Thromb Res 2019;173:35-41.

32. Rattazzi M, Callegari E, Sponchiado A, Galliazzo S, Pagliara V, Villalta S, et al. Visceral obesity, but not metabolic syndrome, is associated with the presence of post-thrombotic syndrome. Thromb Res. 2015;136(2):225-8.

\section{History}

Submitted: 29.10.2020

Accepted after revision: 08.12.2020

Published online: 04.01.2021

\section{Conflicts of interests}

No conflicts of interest exist.

\section{ORCID}

Jamil Nawasrah

(iD https://orcid.org/0000-0002-1199-7665

\section{Correspondence address}

Jamil Nawasrah

Section of Angiology

Department of Cardiology/Cardiology I

University Medical Center Mainz

Johannes Gutenberg University

Langenbeckstr. 1

55131 Mainz

Germany

jamil.nawasrah@unimedizin-mainz.de 